\title{
IS IT POSSIBLE TO IMPROVE THE RELATIONSHIP BETWEEN MARKETING AND SALES?
}

\author{
Kolouchová, D., Rožek, J.
}

Functional cooperation between marketing and sales should be the basic element in all market-oriented companies. This paper investigates the fundamental instruments and tools how to foster the relationship between marketing and sales departments. The authors begin with a review of existing literature in order to gain an overall picture of the respective field. Subsequent qualitative research is based on in-depth expert interviews with midlevel managers. Middle management representatives and their subordinates must interact with the opposite department on a daily basis. Sixty expert interviews reveal that respondents evaluate their relationship with the other department mostly as functional in the way that the common goals are always reached. Research results have shown that the most functional interconnecting elements are the organizational culture that promotes cross-functional communication and information exchange between the representatives of both departments. Very beneficial are common goals, cross functional teams and an open data sharing culture. Effective cooperation should be always endorsed by the top management. At the end, several managerial implications are developed.

JEL classification: M31

Keywords: marketing; sales; management; interfunctional relationship; information flow

\begin{abstract}
Introduction
Fostering the market orientation of the company positively influences the overall competitive position and thus improves the company's overall market performance (Jaworski \& Kohli, 1993; Kotler \& Keller, 2011). Marketing should act as the moderator between the company's internal activities and the external market. This market orientation must be implemented through the whole organization and not only stored within the walls of the marketing department.

The marketing department should be the real business advocate of the corporate culture and market orientation (Kotler, 1977). This role places enormous demand upon marketing in the area of intense cooperation and interaction with all other company departments - marketing should, among its other functions, mainly manage the connections between the company and the customer (Moorman \& Rust, 1999). This marketing function stands fully in line with the global definition of cooperation that is seen as a special form of coordination activity that fosters a common goal, which can be reached by collaborative work (Nabavizadeh, Momeni, \& Saidi, 2013). Marketing stands in this cooperative relationship as the representative of the firm's long-term strategic mission.
\end{abstract}

The strongest cooperation and interconnection is mostly viewed between marketing and the sales department due to the strong customer orientation of both departments (Kotler, Rackham, \& Krishnaswamy, 2006). Nevertheless, this relationship is often the most problematic within the whole organization (Meunier-FitzHugh \& Piercy, 2010) and suffers from misunderstandings and difficulties (Oliva, 2006).

\section{The Importance of Marketing and Sales Integration}

A strong competitive business environment calls for higher internal process effectiveness as one of the competitive advantages creating superior company performance. Improving interdepartmental cooperation is a modern managerial skill. Since both marketing and sales departments are significantly oriented toward the market and the customer, their functional relationship should be the cornerstone in all market-oriented companies (Hulland, Nenkov \& Barclay, 2012). Sales and marketing integration is seen as one of the organizational changes that is most beneficial for sales performance (Miller \& Gist, 2003) and is evaluated as one of the most important issues facing sales and marketing managers 
(Rouziès, 2004). Better cooperation and collaboration of marketing and sales departments definitely leads to higher customer satisfaction and business performance improvement (Meunier-FitzHugh \& Piercy, 2010).

The relationship between sales and marketing is mostly described by poor coordination, dissatisfaction, non-cooperation and lack of cohesion (Dewsnap \& Jobber, 2000). Unfortunately, managers have not paid much attention to this issue for a long time and therefore this problem still persists. As marketing does not nowadays hold its position as the most powerful department within organizations, cooperation with other departments is becoming even more problematic (The Economist Inteligence Unit, 2006).

\section{The Marketing-Sales Relationship: Never a Comfortable Scene}

Dewsnap and Jobber (2000) described the marketingsales relationship as one with a lack of cohesion, poor coordination, full of conflicts, non-cooperation, distrust, dissatisfaction and mutual negative stereotyping. The representatives of these two departments have to cross many barriers to get on with each other. The basic prejudice of marketing departments is that sales is too oriented on each and every customer and thus they lose the overall global market view and long time horizon (Kotler, Rackham, \& Krishnaswamy, 2006). On the other side, sales views marketing as the department, which sits safely away at the office and does not know the reality of the market (Oliva, 2006). Moreover, marketing is an analytical and product-oriented department, with a long-term focus but sales people are heavily resultoriented, with a short-term focus, working mainly in the field (Rouziés et al., 2005). It is all the more serious a problem that reaching long-term goals (e.g., building a strong relationship with customers) nowadays is among the key marketing priorities (Tahal and Stříteský, 2013). In both cases, the basic point as well as the main outcome issue is non-functional communication. The result of such relationships is always the same - decreasing overall effectiveness of both marketing and sales activities (Graham, 2007) instead of gaining synergies from close cooperation.

\section{Background to the Marketing-Sales Conflict}

Before initiating the research we have to outline the socio-psychological background of this long standing rivalry called by Kotler Rackham, \& Krishnaswamy (2006) as the "Montague-Capulet Feud". Dewsnap and Jobber (2000) mentioned two basic theories explaining the interpersonal relationship and the conflict arising in the relation of the two groups - Realistic Group Conflict Theory and Social Identity Theory. The first Realistic Group Conflict Theory determines as the main reasons of conflict the different goals of each group that lead to differentiation of each group's interest and focus. If targets do not correspond or go against each other, the risk of conflict is increasing. The solution of these opposing targets can be setting one common superior target above the individual ones together with ensuring functional and effective communication channels and information exchange between the respective groups. The second Social Identity Theory identified as the main reason of group conflicts the interpersonal identity of each member of the group that is created and formed by the common shared values within the respective community. These group values and statements are strengthened by the comparison with other surrounding groups and their values. This comparison strengthens the intergroup linkages between the members of respective group and increases the differentiation among the other groups.

Dawes \& Massey (2005) studied the variables that have a direct impact on the level of interpersonal conflict between sales and marketing. Based on this research, bidirectional collaborative communication has a significant impact on decreasing the level of interpersonal conflict. And Malshe (2011) remarks that partners in bidirectional communication have to share the same terms and their meaning. The communication frequency is viewed as an essential and important element but this variable increases the level of interpersonal conflict the most. In order to minimize the conflict, it is not enough to seek for high communication frequency but it is more necessary to ensure qualitative and effective forms of communication and teach the members of both groups how to communicate (Dawes \& Massey, 2005). The communication has to take into account all consequences behind the interpersonal interaction. Communication is frequently mentioned as a functional mechanism in the main integration effort (Maltz \& Kohli, 2000; Matthyssens \& Johnston, 2006; Meunier-FitzHugh \& Piercy, 2010; Rafi et al., 2013).

Based on previous studies, five major groups of integration mechanisms can be identified; we used them as the basis for our research:

- Communication

- Cross-functional projects

- Management attitudes towards integration

- Information sharing support

- Organization culture 
Communication has become an irreplaceable part of marketing and sales cooperation. In order to ensure its positive impact, it is necessary to closely manage the communication channels and quality of interpersonal communication flow. Non-managed communication flows never improve the interaction and cooperation (Malshe, 2011).

\section{Research Methodology}

To reveal fostering cooperative behavior between the marketing and sales departments, we have used the grounded theory approach. Qualitative research was selected in order to identify the potential unexplored consequences of the integration efforts in cross functional cooperation. Qualitative research enables one to exploit the existing quantitative findings from previous explorations, interconnect them and further develop them. Qualitative methods allow researchers to focus on the hidden relationship conflict consequences. Expert interviews were used in collecting primary data. In-depth interviews were conducted with managers from local Czech subsidiaries of global firms and locally based companies with local products operating on the local FMCG market. One representative from marketing and one representative from the sales department were interviewed. In total, we conducted 60 interviews. The respondents were selected from the middle management level - mostly Group Brand Managers and Key Account Managers. A clearly determined sales and marketing department with its responsibilities and authority was an important condition in each company. The selection of respondents was based on our business field networking and recommendations within the respective companies. Each respondent had been in his current position for at least two years in order to get managers fully integrated into the internal interpersonal relationships.

As the initial phase, we have distributed among the respondents a short preliminary questionnaire - see Appendix 1, which helped us to get basic knowledge regarding the real cooperation situation, integrating mechanisms and real picture of how conflicts are perceived by sales and marketing managers. The survey served only as the default material for the upcoming expert interview. They were not used for further explanatory work nor findings summary. The interviews were conducted face-to-face mostly in the offices of the respondents and each interview took a maximum of 60 minutes. The semi-structured research scenario covered three main topics - crossfunctional collaboration, interpersonal conflict with a special focus on interconnecting mechanisms, and the role of communication within these processes.

The subsequent research data analysis was conducted based on the detailed interviewer's notes from each interview transcribed into the electronic form with the help of the audio records of each interview. Based on this data groundwork, we have used the coding methodology in order to extract and code the key-points from the respective interviews. Selected key-points were subsequently compared with the codes from the rest of the interviews using the comparison method in order to get a higher level of data abstraction. This process enabled us to select the theoretical notes and create the researcher reflections based on the memoing process from the outcomes of the previous steps.

\section{Research Findings}

There have been numerous opinions and arguments for effective communication from the side of both marketing and sales respondents. The major contribution of this research is the formulation of the individual integrating elements which support the collaborative working environment. Most of the respondents considered their relationship with the other departmental representatives as functional and effective. The cooperation is effective in the way that the common tasks and goals are always reached, in most cases by teamwork and collaboration. On the other hand, this fact does not mean that there are no misunderstandings and conflicts between sales and marketing. Harmonious working relationships were not found anywhere.

As interconnecting mechanisms of functional relationships, the following were mentioned: evaluating and rewarding system and cross sales-marketing projects. The rewarding system should implement common goals with common responsibilities. Common targets must be realizable with the same effort of both sides and a fulfilled objective must be rewarded identically. This approach enforces cooperation, helps to find effective solutions and forces people to communicate. Regarding cross salesmarketing projects, management should use either hard or soft influence tactics in cooperative tasks. Common goals destroy barriers, improve communication and interdepartmental respect, increase competences and help to understand the work focus, priorities and challenges of other department. Most managers mentioned that cross sales-marketing projects have a strong synergetic effect especially when the team is nominated from people who already have a similar mind-set and good informal relationships. On the other hand, some of them mentioned that invention of common rewarding system for common goals is a bit time consuming. 
Low knowledge of the work of the opposite side is another significant source of conflicts. This problem was noticed only during interviews with sales managers. Unfortunately, in the case of sales people, this knowledge gap is associated with the underestimation of marketing staff competences. The request of sales or field experience for marketers was registered in every interview with sales managers. The marketing department is interested in sales processes and sales priorities mainly because they want to get an alignment between marketing and sales objectives. Marketers mentioned the different hierarchy of priorities as among the most frustrating barriers.

The research focus was set on the communication element and its role in the process of cooperation improvement. A majority of the respondents mentioned communication as one of the most functional integrating elements. The communication has to respect two conditions: it has to be bidirectional and must avoid information overload. The communication creates a base for all integrating efforts, which corresponds with the previous quantitative research. On the other hand, functional cooperation is a result of a complex system in which communication plays the role of mediator.

The research emphasized the irreplaceable role of an organizational culture that promotes and enhances open cross-functional collaboration, free information, data and analysis sharing and free communication flow. Members of both departments should have access not only to the hard data gathered and processed by the other department. It is also important to have access to the soft information and have the possibility to understand the consequences of this knowledge and be able to work with it. Our research found that, in most cases, the members of the respective departments do not have a full access to the information from the other department. Even more, most of the respondents stated that they have to hide some information from the other department. The most cited reason for hiding information was the exact budget allocation. Marketing hides spending for less effective image building projects and sales hides huge client discounts, which help to fulfil their short-term volume targets. This fact leads to the so-called "closed doors policy" and in the end harms the trust and cooperation efforts of the management. Effective information flow and open data sharing are perceived as a must for effective decisions. Both departments are aware that actual market knowledge is crucial for company success.

There was almost a full consensus that top management has to fully support the integrating mechanisms between marketing and sales. Managers have to act as advocates of these efforts. A key task is to create and enhance an organizational culture that supports free information and data sharing. One of the most effective and functional methods to establish such a culture is to set up, promote and share one common vision of the company with employees from all departments. One important element is the hiring process in which managers should focus on the way the applicant works on a team and on how he or she fits into the existing culture of the company. The research confirmed that many interviewed managers already focus on this element during the selection process of new employees.

\section{Managerial Implications}

This study should foster the integrating mechanisms between sales and marketing. In their collaboration, however, there are many obstacles that reduce their performance and output quality. We see it as absolutely necessary that managers pay attention to this problem. The following advice and recommendations were identified based on expert interviews. The communication appears as a mediator for the integration efforts although it cannot be taken as the salvation on its own. Moreover it needs to be managed, it needs to avoid overloading side effects and it has to respect bidirectional flow.

The important part of the integrating attempts should rest on information exchange and data sharing mechanisms which save time for both sides. The managers must take a leading role in the process of free data flow, and they have to ensure that neither of the departments hides any information from the other. Each hiding of data, which sooner or later come to light, ends with a remarkable deepening of interdepartmental mistrust. The position of sales and marketing departments in terms of access should be on the same level - both horizontally between each other and vertically from the top management to the specialists or sales representatives, of course with the respect to the secret strategic decisions.

The integrating approaches should not be reduced only to hard mechanisms in the form of cross-functional teams or remuneration methods. The cooperation efforts must become a regular working habit for the whole company through all teams down to each employee. There is again an important role of the top management. It should set the basic principles of functional cooperation, create the processes, leverage the corporate culture change and of course became a visible representative of newly set cooperative environment.

\section{Conclusion and Future Research Propositions}

Marketing and sales represent two strongly connected departments. The strengthening of cooperative behavior between sales and marketing could be appropriately 
and effectively supported in different areas. Our study has shown strong barriers to building collaborative relationships between sales and marketing but it has also offered some tools to break down the barriers that separate these two departments. It pointed out the significant role of top management, which has to take responsibility for creation and enhancement of the cooperative relationship. Besides a common rewards system and cross sales-marketing projects, there is a strong need for a corporate culture that supports free information flow and data sharing. Our study has shown the significant role of the management and companies' top management, which could be a relevant target group for future quantitative studies in order to find out how irksome marketing-sales conflicts are for CEOs.

\section{References}

Dawes, P. L., Massey, G. R. (2005). Antecendents of Conflict on Marketing Cross-functional Relationship with Sales. European Journal of Marketing, 39 (11/12): 1327-1344.

Dewsnap, B., Jobber, D. (2000). A Social Psychological Model of Relations Between Marketing a Sales. European Journal of Marketing, 36 (7/8): 874-894.

Graham, V. W. (2007). Aligning sales \& marketing for dynamic growth. SuperVision, 68 (10): 14.

Hulland, J., Nenkov, G. Y., Barclay, D. W. (2012). Perceived Marketing-Sales Relationship Effectiveness: A Matter of Justice. Journal of the Academic Marketing Science, 40: 450-467.

Kotler, P., Keller, K. (2013). Marketing Management. Prague: Grada.

Kotler, P., Rackham, N., Krishnaswamy, S. (2006). Ending the War between Sales \& Marketing. Harward Business Review, 84 (7/8): 68-78.

Malshe, A. (2011). An Exploration of Key Connections within Sales-Marketing Interface. Journal of Business \& Industrial Marketing, 26 (1): 45-57.

Jaworski, B. J., Kohli, A. K. (1993). Market Orientation: Antecedents and Consequences. The Journal of Marketing, 57 (3): 53-70.

Maltz, E., Kohli, A. K. (2000). Reducing Marketing's Conflict with Other Functions. Journal of Academy of Marketing Science, 28 (4): 479-492.

Matthyssens, P., Johnston, W. J. (2006). Marketing and Sales: Optimization of a Neglected Relationship. Journal of Business \& Industrial Marketing, 21 (6): 338-345.

Meunier-FitzHugh, K. L., Piercy, N. F. (2010). Improving the Relationship Between Sales and Marketing. European Business Review, 22 (3): 287-305.

Miller, T. G., Gist, E. P. (2003). Selling in Turbulence Times. New York: Accenture-Economist Inteligence Unit Survey.
Nabavizadeh, R., Momeni, M., Saidi, S. S. (2013). The Impact of Aligned Rewards and Senior Manager Attitudes on Conflict and Collaboration between Sales and Marketing in JahanBehbood Pharmaceutical Co. International Research Journal of Applied and Basic Sciences, 5: 756-761.

Oliva, R. A. (2006). The Three Key Linkages: Improving The Connections Between Marketing and Sales. Journal of Business \& Industrial Marketing, 21 (6): 395-398.

Rafi, A., Saleem, Y., Iqbal, J., Iftikhar, A., Nawaz, M. (2013). Collaboration Between Sales and Marketing Increases the Business Performance: Evidence from Pakistani export industry. International Journal of Research in Commerce and Management, 4 (2): 46-50.

Rouziès, D. (2004). Observatoire de la relation marketingcommercial. White paper, ADETEM, BT-Syntegra, HEC-Paris, Microsoft and Novamétrie, (accessed August 28, 2014), [available at https://www.google.com/ webhp? $\mathrm{rct}=\mathrm{j} \# \mathrm{q}=$ Observatoire $+\mathrm{de}+\mathrm{la}+$ relation + marke ting-commercial].

Rouziès, D., Anderson, E., Kohli, A. K., Michaels, R. E., Weitz, B. A., Zoltners, A. A. (2005). Sales and Marketing Integration: A Proposed Framework. Journal of Personal Selling \& Sales Management, 25 (2): 113-122.

Tahal, R., Stříteský, V. (2013). Building the Effective Loyalty Program. In: Basl, J., Jašek, P., Novotný, O., Tjoa, A Min (ed.). Confenis-2013. Prague, 11. 09. 2013 - 13. 09. 2013. Linz: Trauner Verlag, 251-258.

The Economist Inteligence Unit. (2006). The future of marketing From monologue to dialogue. Economist Intelligence Unit white paper sponsored by Google [online]. London: The Economist Intelligence Unit, (accessed August 28, 2014), [available at http:// graphics.eiu.com/files/ad_pdfs/Google_Future_of_ Marketing_060907.pdf].

$$
\begin{array}{r}
\begin{array}{r}
\text { Authors } \\
\text { Ing. Daniela Kolouchová } \\
\text { Assistant Professor } \\
\text { Department of Marketing }
\end{array} \\
\text { Faculty of Business Administration } \\
\text { University of Economics, Prague } \\
\text { W. Churchill Sq. 4, 13067 Prague, Czech Republic } \\
\text { daniela.kolouchova@vse.cz } \\
\text { Ing. Jan Rožek, MIM } \\
\text { Key Account Manager at Nutricia } \\
\text { Post-graduate student of Marketing } \\
\text { Faculty of Business Administration } \\
\text { University of Economics, Prague }
\end{array}
$$

The paper is a result of a research project IG306014. 


\section{Appendix 1 Pre-test survey questionnaire}

1. Evaluate the frequency of cooperation between the marketing and sales departments on a scale from $1-7(1=$ very frequent $/ 7=$ no cooperation)

\begin{tabular}{|l|l|l|l|l|l|l|}
\hline 1 & 2 & 3 & 4 & 5 & 6 & 7 \\
\hline
\end{tabular}

2. Evaluate the quality of cooperation with the other department (marketing or sales) on a scale from 1-7 $(1=$ great with no issues $/ 7$ = problematic with many issues)

\begin{tabular}{|l|l|l|l|l|l|l|}
\hline 1 & 2 & 3 & 4 & 5 & 6 & 7 \\
\hline
\end{tabular}

3. What are the situations in which you experience the biggest misunderstandings in cross-functional cooperation? Arrange the situations listed below starting with the biggest misunderstanding up to the smallest one. $(1=$ biggest, $2=$ second biggest...) If you do not experience any of the selected situations, mark it N/A.

\begin{tabular}{|l|l|}
\hline Cross-functional situations & Issue Experience \\
\hline Situation analysis and research & \\
\hline Strategy planning & \\
\hline Tactical planning & \\
\hline Strategy implementation & \\
\hline HR management & \\
\hline Outcomes controlling and evaluation & \\
\hline Internal / external communication & \\
\hline Others - please describe... & \\
\hline
\end{tabular}

4 Arrange the listed misunderstanding causes based on the occurrence within your cross functional cooperation. $(1$ = highest occurrence; 2 = second highest occurrence...). If you do not experience any of the selected situations, mark it N/A.

\begin{tabular}{|l|l|}
\hline Misunderstanding causes & Occurrence \\
\hline Different goals and targets & \\
\hline Different personalities & \\
\hline Different educational level and education scope & \\
\hline Physical separation of both departments & \\
\hline Insufficient information and data sharing & \\
\hline Insufficient knowledge about the other department work & \\
\hline Stereotypes & \\
\hline Vague cross-functional cooperation rules & \\
\hline Insufficient coordination as an effect of non-functional top management level communication & \\
\hline Unfair budget assignment & \\
\hline Others - please describe... & \\
\hline
\end{tabular}

5. What are the three main causes that obstruct effective cooperation and why?

\begin{tabular}{|l|l|}
\hline Misunderstanding cause & Why? Please try to be as concrete as possible \\
\hline & \\
\hline & \\
\hline
\end{tabular}


6. Are there any managerial attitudes in order to improve the cross-functional cooperation?

o YES

o NO

7. What forms of cooperation improvement are used in your company? Arrange the situations listed below starting with the most frequent up to the lowest. $(1$ = highest, 2 = second highest...) If you do not experience any of the selected forms, mark it N/A.

\begin{tabular}{|l|l|}
\hline Forms of improvement & Frequency \\
\hline Deeper integration efforts, creation of cross-functional positions & \\
\hline Implementation of cross-functional project teams consisting of members of both departments & \\
\hline Supporting informal relations through teambuilding etc. & \\
\hline Common evaluating criteria, bonus system supporting cross-functional cooperation & \\
\hline $\begin{array}{l}\text { Creation and maintenance of corporate culture that supports cooperation and open communication } \\
\text { atmosphere }\end{array}$ & \\
\hline Learning organization-data sharing, best practice sharing, united data and knowledge base & \\
\hline Employee rotation within the departments & \\
\hline Others - please describe & \\
\hline
\end{tabular}

8. What are the three main forms that support cooperation and why?

\begin{tabular}{|l|l|}
\hline Forms of improvement & Why? Please try to be as concrete as possible. \\
\hline & \\
\hline & \\
\hline & \\
\hline
\end{tabular}

9. Is there any information that you have to hide from the other department?
o YES
o NO

10. What department stands for the more powerful one in the process of strategy creation?
o Marketing
o Sales

11. What department provokes conflicts more often?
o Marketing
o Sales

12. What department is the first one trying to proactively solve a conflict that has arisen?
o Marketing
o Sales

Source: Authors 